\title{
reviews
}

\section{Reading about self-help for schizophrenia}

There is a deluge of written information for users and carers being produced about schizophrenia, which shows no sign of abating, so this article makes no attempt to be comprehensive. It would be out-ofdate by the time of publication and would inevitably miss leaflets cherished by individual psychiatrists, mental health workers, users and carers. However, remarkably few up-to-date books exist and this issue will be discussed later in the article.

Initially we examined leaflets and small booklets that were available in summer 2002. We gave two groups of service users - with three service users in each group - some examples of the literature available from the range of sources dispensing it; the Government, professional bodies, pharmaceutical companies, voluntary groups and local services. They were asked to view the materials and make comments about them; what they felt was useful and if they felt that anything was missing or unhelpful; what they felt was relevant to them and what made them want to read on or put a leaflet down and if they found anything particularly frightening and/or thought provoking. They were also asked for their thoughts about the need for this literature: if they felt there was such a need, to reflect on when they felt it would have been helpful for it to be offered to them in their treatment programme. They were asked to comment as to when they felt it should, if at all, be offered to others with psychosis; and if they felt it would benefit others in their treatment, or if they had been newly diagnosed.

Group one consisted of acute service users: two clients had been in the service for several years and the other was newly diagnosed. The second group consisted of three clients from a rehabilitation unit. These differences were reflected in the dynamics within the groups and contributed to the agendas and the 'personality' of the groups. Group one was a lively group, questioning the articles and challenging the mental health system generally - suggesting ways of how they felt things should change. Group two were more accepting of what was presented and the care they received. In group one all of the clients were having, or had had, some form of psychosocial intervention. In group two only one client had. Consequently, group one was able to reflect on some specific work done regarding psychoeducation, relapse prevention, family work and previous work done on the management of symptoms and relate it to their personal experience and the benefits of having these interventions. Group two seemed more accepting of their diagnoses. They had been less able, or felt less need, to challenge and question and give their opinions on issues. They highlighted the importance of legal aspects of care and information concerning this was important to them as it helped to influence the decisions they had to make. There was very little legal information within the leaflets that was of any practical use unless the clients had access to the Internet (although statutory leaflets should have been available to them).

One client initially said he felt no need for information leaflets. He said 'that having these materials would not have made any difference to him and his illness' and said he felt that 'there isn't a point to them.' But later this same client, reflecting on his own experiences said that when he had been sectioned and 3 months later given a diagnosis of schizophrenia, the diagnosis had not been explained to him initially and that had he had more information things might have been easier. Later he reflected that when a nurse went through his specific symptoms he had found this helpful.

Common themes identified by both groups included that years ago, at the onset for some of them of their illnesses, there was nothing like the material under discussion made available to them. One client said that if she had had this information 5 years ago 'I would not have had to spend the last 5 years learning ways of coping with the symptoms myself, but she also stated that you would have to actively seek out these leaflets. The material was still not readily available for clients and should be made more accessible in areas such as admission wards, GP surgeries and in community mental health clinics. Both groups agreed that the leaflets with too much information and clinical language would prevent them from reading on

The term 'schizophrenia', which was on all the leaflets considered by the groups, initiated fear and they identified this with press reports of people who are 'dangerous'. They felt this stigmatised the word and therefore the people who were labelled with it. One client asked 'Can't another term be used to describe symptoms?'. They questioned whether it was necessary to use such a label and that the focus should be on symptom management, giving ways for each of them to do this.

All agreed that presentation and simple, easy-to-read material with good lay out was important as the illness can affect concentration. Some material was

regarded by both groups as hard to read 'I wouldn't get by the first page... I would need a dictionary to help'. 'It's longer than a DLA form'. The Insight into Schizophrenia brochures were initially discarded by both groups until they were identified as a series of booklets. (The prominence of the term 'schizophrenia' had previously been found off-putting.) Group one found them 'understandable and easy to relate to themselves, with at least one of the booklets being relevant to all of them'. One client said the drugs and alcohol leaflet was important to him and people like him, and commented that 'drug abuse and mental illness is a big issue - do drugs cause mental illness or do the drugs bring the illness out?' Group two was accepting of the term 'schizophrenia' but one member did find the 'severe and enduring mental illness' title frightening.

An issue that group one felt strongly about was that all the literature viewed lacked positive statements, e.g. that the illness can be managed. One client said that 'it is important that she manages the symptoms rather than the symptoms managing her'; another said that it is important to emphasise that 'living with psychosis is not all doom and gloom' and people reading the literature needed to be encouraged positively

A group one member reflected on past family psychoeducation work. She had found going through material with a professional was helpful. She reflected that the literature was tailored by the workers to her and her symptoms and she said that she and her family had found this individualised approach beneficial. She remembered that the worker had been able to allay fears arising from the content of the literature brought up with her parents and herself immediately in the session which she said was helpful. Both groups identified relapse prevention as crucial.

The members of the focus groups took different things from different booklets depending on their stage of illness. As well as having the materials, the clients said they needed someone to explain terms, clarify explanations and support them as their insight improved. Although the simple well laid out leaflets were popular, they did not do the whole job and it seems there is no substitute for a well-informed mental health professional to supplement these materials and help the client deal with the consequences of the facts they learn from them.

Soon after completion of this project, the National Institute for Clinical Excellence (NICE) produced clinical guidelines on schizophrenia. These include 


\section{Box 1. Examples of psycho-education materials provided}

Mental Illness; What does it mean?

Department of Health

A leaflet with general explanations of a variety of specific mental illnesses looking to reduce the stigma and misconceptions associated with mental illness. The booklet was described by the user groups as easy to read and a good introduction to the subject, but because of the wide range of topics covered there was little detail that was useful.

\section{Schizophrenia. Help is at hand series}

The Royal College of Psychiatrists (Available via website)

A factual document describing the basic facts, symptoms, causes and treatments for schizophrenia. This leaflet was liked by the groups as it was easy to read and provided good information, particularly for those who are newly diagnosed and looking for more information on their illness.

\section{What is severe mental illness?}

National Schizophrenia Fellowship

Pamphlet containing descriptions of schizophrenia, depression, manic depression and personality disorder with information on how the NSF can help. Again the booklet was described as easy to read and a good introduction to the topic but because of the wide range of topics covered there was little detail that was useful.

\section{Information pack including 'A beginner's booklet about schizophrenia', and newsletter and various articles \\ Schizophrenia Association of Great Britain}

A comprehensive pack of information that both groups found difficult to navigate due to the quantity of information that was presented to them. The information is very detailed with a significant amount of legal governmental and forensic material that the group said was difficult to concentrate on and not relevant to their needs.

\section{Insight into Schizophrenia booklets}

Pfizer (now NiMHE)

A series of six 5 booklets containing information and advice on aspects of schizophrenia. After initial uncertainty especially about the emphasis on 'schizophrenia', both groups found this set of booklets contained useful information and was easy to navigate. The layout was simple and easy to read but with enough detail to be helpful to both those who have been newly diagnosed and those who have suffered for many years.

\section{What is Schizophrenia?}

Local Healthcare NHS Trust

Leaflet produced by the local rehabilitation service and department of psychological therapy. This was a detailed booklet that the group felt was too technical and didn't catch the eye. It was quickly put back on the pile of booklets provided by those who tried to read it.

well-written leaflets on the subject for users and carers, which fortunately correspond in many ways to the preferences expressed above.

Finding relevant books is much more difficult. Searching small and large bookshops in various towns and cities over the past few months has been almost fruitless. The Internet book companies do have numerous books on schizophrenia, but the overwhelming majority are specifically for professionals rather than users and carers, with rare exceptions. None are aimed predominantly at 'self-help'. Those that do exist tend to be out-of-date (i.e. more than 10 years old) or lacking in consideration of newer developments in pharmacology and psychosocial interventions. Exceptions include Surviving schizophrenia by Fuller Torrey (2001) and Schizophrenia: the facts by Tsuang \& Faraone (1997), which provide a wealth of information about symptomatology and aetiological theories. The former considers cognitive behaviour therapy briefly but relatively dismissively (unlike the NICE guidelines) and the latter not at all. Family work is better covered in books specifically for carers, such as A carer's guide to schizophrenia by Wilkinson and colleagues (1999).

Reviews of studies of psychoeducation have found it to be beneficial (e.g. Pekkala \& Merinder, 2000) but there has been some suggestion that it may increase suicidal ideation (Cunningham-Owens et al, 2001). The books reviewed tend to be rather gloomy and instil little hope. Although schizophrenia can be a devastating illness, there is wide variability in outcome and promising new developments in management reflected in the increasingly positive studies of outcomes in community services (Harrison et al, 2001). (It may also be that if somebody has sufficient energy and interest to seek out and read these books, their prognosis will be better than average.)

Terminology can be a block - as described above - so a book such as Living with mental illness by Kuipers \& Bebbington (1987) may be useful and acceptable as this does focus on severe mental illness primarily (although it is again rather than dated). Accepting voices by Romme \& Escher (1993) is also worth considering. It is rather a dense read but it does describe individual experiences and some of the ways, many innovative and unconventional, that people have learnt to understand and cope with their voices. Schizophrenia: the positive perspective by Peter Chadwick (1997) contains much wisdom from an eloquent user of services.

Some texts for professional staff may also be worth considering, given the limitations with those specifically for users, e.g. those by Murray and Frangou (2002) and by Birchwood (2001) for general information, and specifically for newer treatment approaches those of Kingdon \& Turkington (1994: 2002) which are aimed at appropriately normalising symptoms of schizophrenia.

Currently, there does seem to be a lack of accessible, up-to-date and practical books to empower users to understand and take control of their situation and distressing symptoms. Self-help for schizophrenia might have seemed a contradiction in terms a decade ago when all-or-nothing beliefs about insight prevailed - how can someone lacking insight help themselves? As it has become clearer that users can and do become agents in their own recovery, understanding of this and how they do it needs greater dissemination so that others can take advantage of these experiences Leaflets can help and need to continue to be developed along the lines described but more comprehensive, well-written and readily available information on selfhelp principles and practice would be invaluable.

\section{References}

BIRCHWOOD, M. \& JACKSON, C. (2001) Schizophrenia. Philadelphia: Psychology Press.

CHADWICK, P. K. (1997) Schizophrenia: the positive perspective. London: Routledge.

CUNNINGHAM OWENS, D. G., CARROLL, A., et al (2001) A randomized, controlled trial of a brief interventional package for schizophrenic outpatients. Acta Psychiatrica Scandinavica, 103, $362-369$. 
HARRISON, G., HOPPER, K., CRAIG, T., et al (2001) Recovery from psychotic illness: a 15 and 25 year international follow-up study. British Journal of Psychiatry, 178, 506-517.

KINGDON, D. G. \& TURKINGTON, D. (1994) Cognitive behavior therapy of schizophrenia. NewYork: Guilford.

KINGDON, D. G. \& TURKINGTON, D. (2002) A case study guide to cognitive therapy of psychosis. Chichester: John Wiley \& Sons.

MURRAY, R. \& FRANGOU, S. (2002) Schizophrenia. London: Martin Dunitz.

PEKKALA, E. \& MERINDER, L. (2000)

Psychoeducational interventions for schizophrenia and other severe mentali illnesses. (Cochrane Collaboration.) Oxford: Update software.

ROMME, M. \& ESCHER, S. (1993) Accepting Voices. London: MIND.

TORREY, F. E. (2001) Surviving Schizophrenia. New York: Harper Collins.

TSUANG, M. M. \& FARAONE, S.V. (1997) Schizophrenia: the facts. Oxford: Oxford University Press.

WILKINSON, G., KENDRICK, A. \& MOORE, B. (1999) A carer's guide to schizophrenia. London: Royal Society of Medicine.

Relevant websites (accessed 15 June 2003) http //www emental-health.com/ schizophrenia. asp (General information). http://www.hearingvoices.org.uk/users.htm (Information from the Hearing Voices network and links).

http://www.nice.org.uk/pdf/CG1publicinfo.pdf (Information with NICE guidelines). http://www.openthedoors.com/ (TheWorld Psychiatric Association website about schizophrenia) http:/www.rcpsych.ac.uk/info/schiz.htm (The College's leaflet on schizophrenia)

David Kingdon Professor of Mental Health Care Delivery, University of Southampton, Royal South Hants Hospital, Southampton SO14 OYG (dgk@soton.ac.uk), Paul Murray Research Nurse, University of Southampton, Elaine Doyle Community Psychiatric Nurse, Isle of Wight Mental Health Services

\section{Schizophrenia. \\ Full National Clinical \\ Guideline on Core \\ Interventions in Primary and \\ Secondary Care \\ National Collaborating Centre for Mental Health}

London: Gaskell, 2003, £50 pb, including 2 CD-ROMs, 264 pp.,
SBN: 1-901242-97-8, Book ID: 1747

National schizophrenia guidelines with some relationship to evidence are overdue. These guidelines are underpinned by substantial critical appraisal of the literature, which is then embedded in thoughtful, concise synopses. The presentation is clear, well-structured (if not indexed) and attractive, and enhanced by one training $C D$ and another containing relevant data. The document is easy to read, represents important progress and should be used, at the very least, by everyone interested in the care of people with schizophrenia in England and Wales. But there are caveats. Several. Bits are missing, open to misinterpretation, biased, and verging on the ridiculous. Intentionally, the guide does not cover care of the elderly or very young. It does not contain information on the management of common adverse effects, surprisingly little on early intervention services and treatment issues of people with concurrent depression, learning disability, personality disorder, physical ill health or/and substance misuse. Management problems relating to legal or forensic issues are not tackled. But then you cannot do everything in one document. Perhaps the ambiguous 'full' of the title refers to the nations and not the scope of care. It is therefore redundant; one would hardly expect Yorkshire or

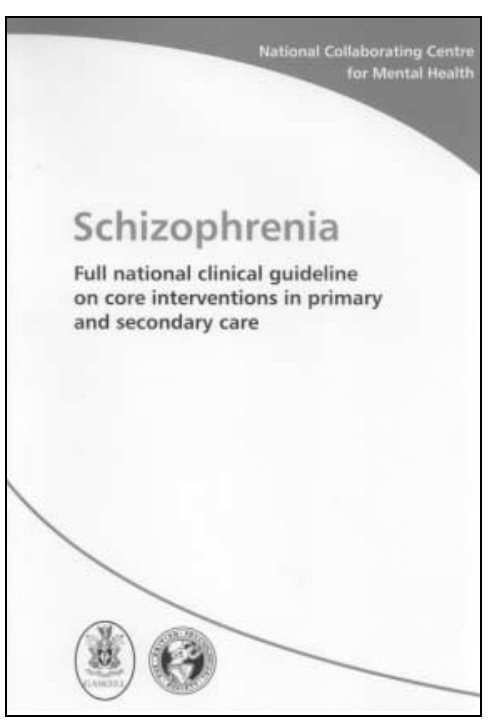

Yeovil, for example, to be exempt. Perhaps the title's 'core' is also debatable.

The guidance about the use of oral atypicals has already been misinterpreted. It recommended that expensive new drugs are considered in the choice of firstline treatments for people with newlydiagnosed schizophrenia (5.2.7.7). It did not recommend that they are the first-line choice as is implied by some rosettebedraggled advertising. Older inexpensive atypicals are not precluded, and neither are first generation drugs given in adequate but not excessive doses (5.2.7.3).

The guidance on rapid tranquillisation may betray biases. The reporting of one olanzapine study seemed excessive covering half a page with uninterpretable figures (5.5.4). This prompted me to use the accompanying CD to seek the source study. I do not have space here to fully appraise this shameless industry vehicle, but why it is given such exposure, considering there are so many other shameless industry vehicles in competition, smacks of successful 'interested' lobbying.

Reading the guideline, I did not expect to laugh, but did. They say audit could take place to monitor compliance with recommendations for, among many other things, family interventions and cognitivebehavioural therapy (CBT, Table 8.1). Family interventions ( $>10$ sessions, $>6$ months) are to be offered to everyone with schizophrenia - and everyone with persisting psychotic symptoms should have CBT ( $>10$ sessions, $>6$ months). These recommendations stem from trial data showing modest declining effects that fail to report adverse effects and interventions given mostly by highlyskilled motivated teams. These silly unrealistic recommendations devalue both the therapies and guidelines.

These guidelines should be successful in assisting clinicians and patients make decisions about appropriate treatment (1.1.1). I am not at all convinced, however, that they will be the same decisions as those suggested in these guidelines. Nevertheless this important work encourages decisions to be made carefully and rationally. That seems like progress.

Clive E. Adams Chair of Adult Psychiatry University of Leeds, Co-ordinating Editor, Cochrane Schizophrenia Group 